\title{
Ensaio fotográfico Arte na trilha
}

\author{
Flavio Augusto da Silva Contente \\ Uirá Seidl Pinheiro \\ Ariadne da Costa Peres Contente
}

\section{Apresentação}

nter-relacionar as práticas de educação, o lúdico e o meio
ambiente em uma dinâmica diferenciada no processo ensino-aprendizagem nos anos iniciais, constitui o objetivo do Circuito em Educação Ambiental - Arte na Trilha, um projeto que convida alunos de diferentes níveis de ensino a oportunidade de tornarem-se desbravadores mirins em uma viagem pelo imaginário amazônico entrelaçando em diversas áreas, saberes e conhecimentos que envolvem a temática ambiental.

Neste sentido, personagens do imaginário local como a Matinta Perera, a Índia Amazona, o Curupira, a Cobra grande e o Mapinguari - seres místicos da floresta - irão conduzir o alunado pela trilha "IMIRA" (que significa "entrando na mata no dialeto TUP"), em uma proposta inovadora de aprendizado no qual o lúdico por meio das transversalidades temáticas, cria interfaces com o saber tradicional e o científico, objetivando facilitar o entendimento dos alunos quanto às questões culturais, sociais e ambientais.

Ao longo das atividades da trilha ecológica interativa, montada como um misto de jogo e espetáculo teatral, com roteiro inspirado nas lendas amazônicas, os participantes são levados a entender a importância da preservação e conservação da flora, da 
fauna e tudo que permeia a vida no contexto local. De forma complementar a trilha, oficinas de teatro, oficinas em artes plásticas, oficinas de musicalização e de fotografia incentivam aos desbravadores mirins a reflexão, o desenvolvimento da criticidade, da cidadania planetária, de habilidades e das competências necessárias e da participação colaborativa.

O projeto metodologicamente se propõe a colaborar e somar com o currículo diversificado das escolas públicas do Pará, tendo em vista as orientações do Conselho Nacional de Educação (CNE) e do Programa Estadual de Educação Ambiental do Estado do Pará (PEAM), com objetivo de fortalecer conhecimentos e estimular movimentos nas escolas de práticas educacionais e ambientais alternativas.

O Circuito em Educação Ambiental - Arte na Trilha, desenvolvido pelo Instituto Ariri Vivo conta com o apoio da Lei Semear da Fundação Tancredo Neves e do Grupo Líder, que acreditando na proposta de sensibilização ambiental por meio de práticas educativas diferenciadas e da formação cidadã viabilizaram o financiamento permitindo a sua execução. 

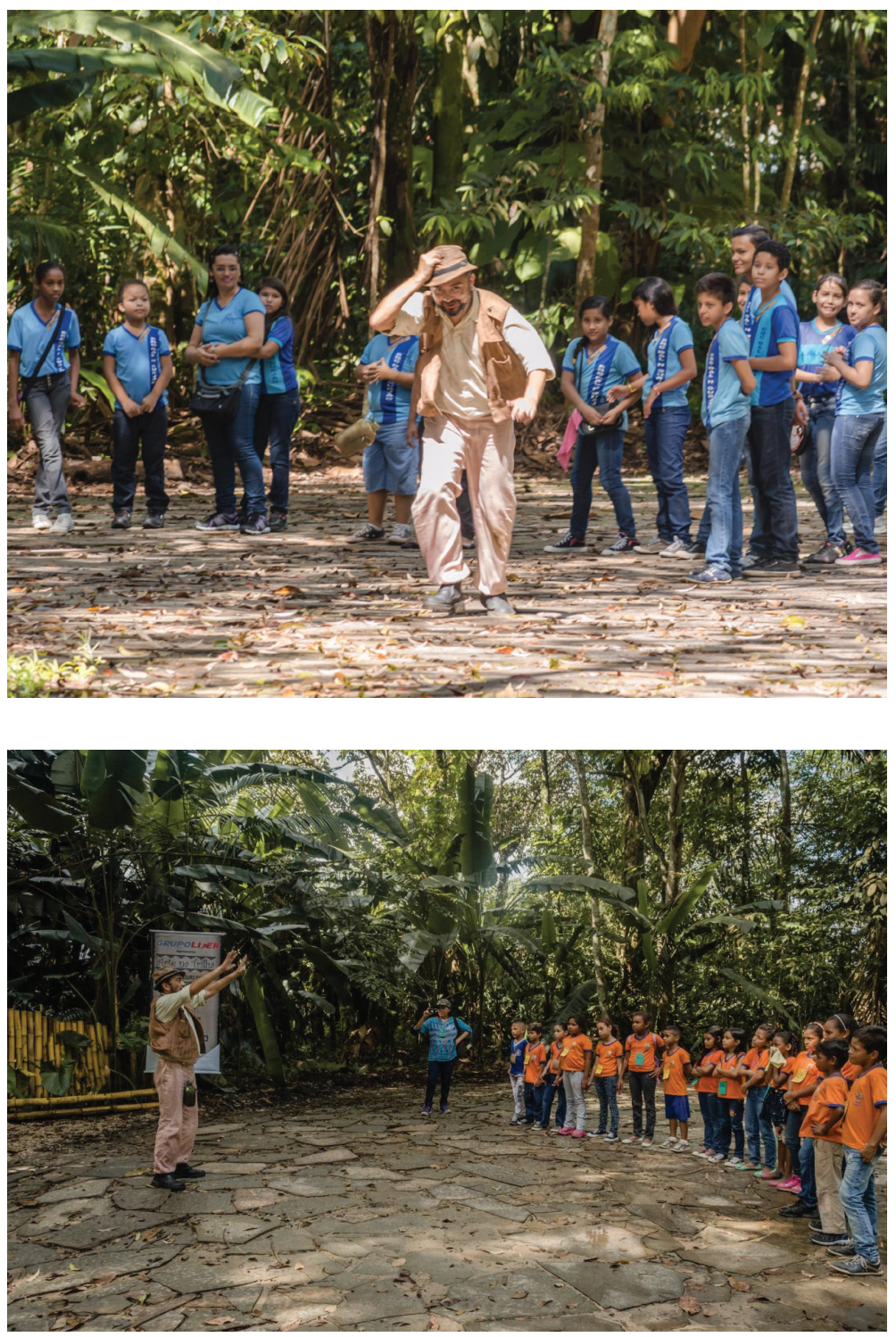
58 EXPERIMEN T $\bigwedge$ R T Ano 2-n. 3-jul./dez. 2016 - ISSN 2526-7736

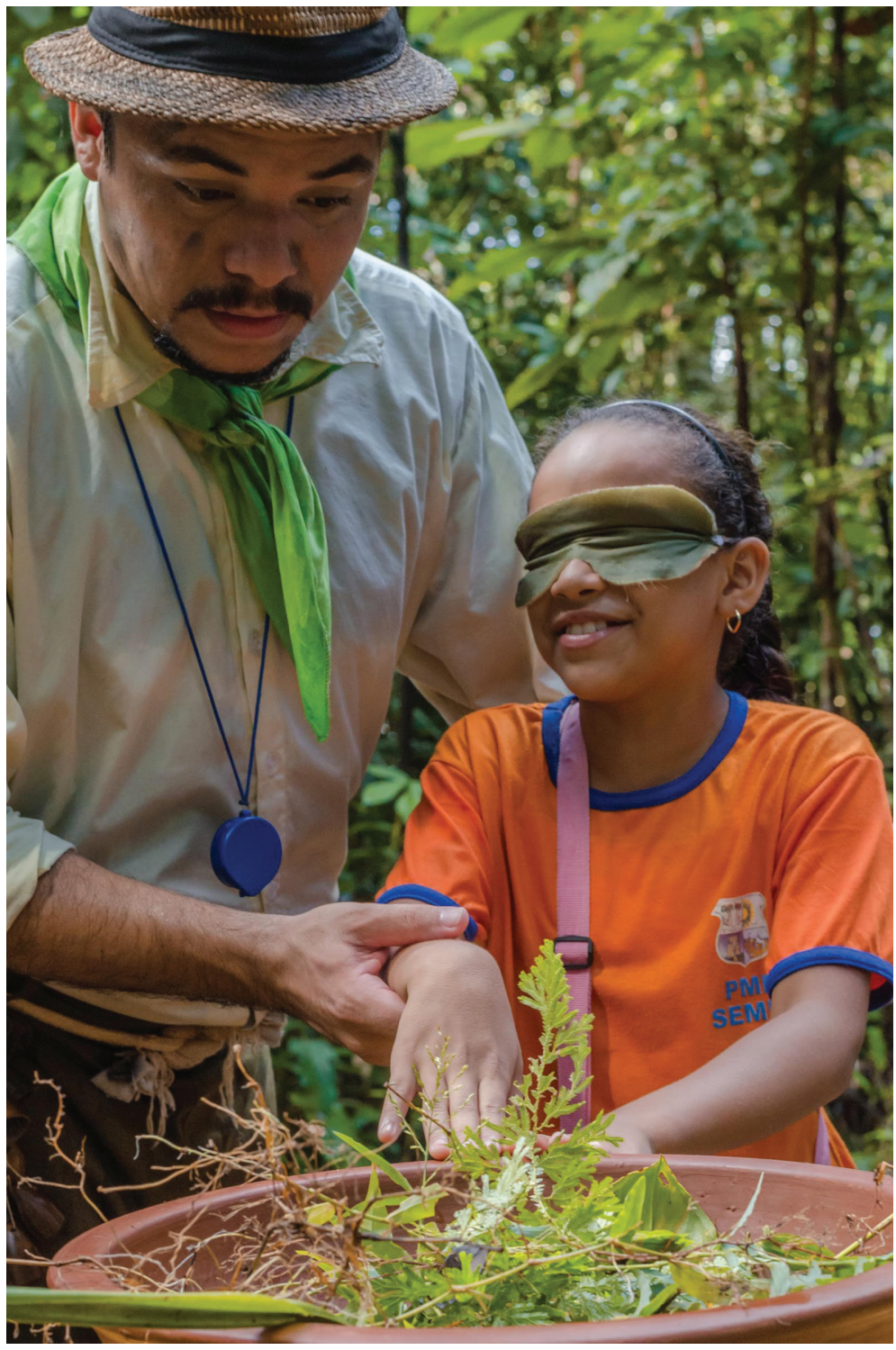




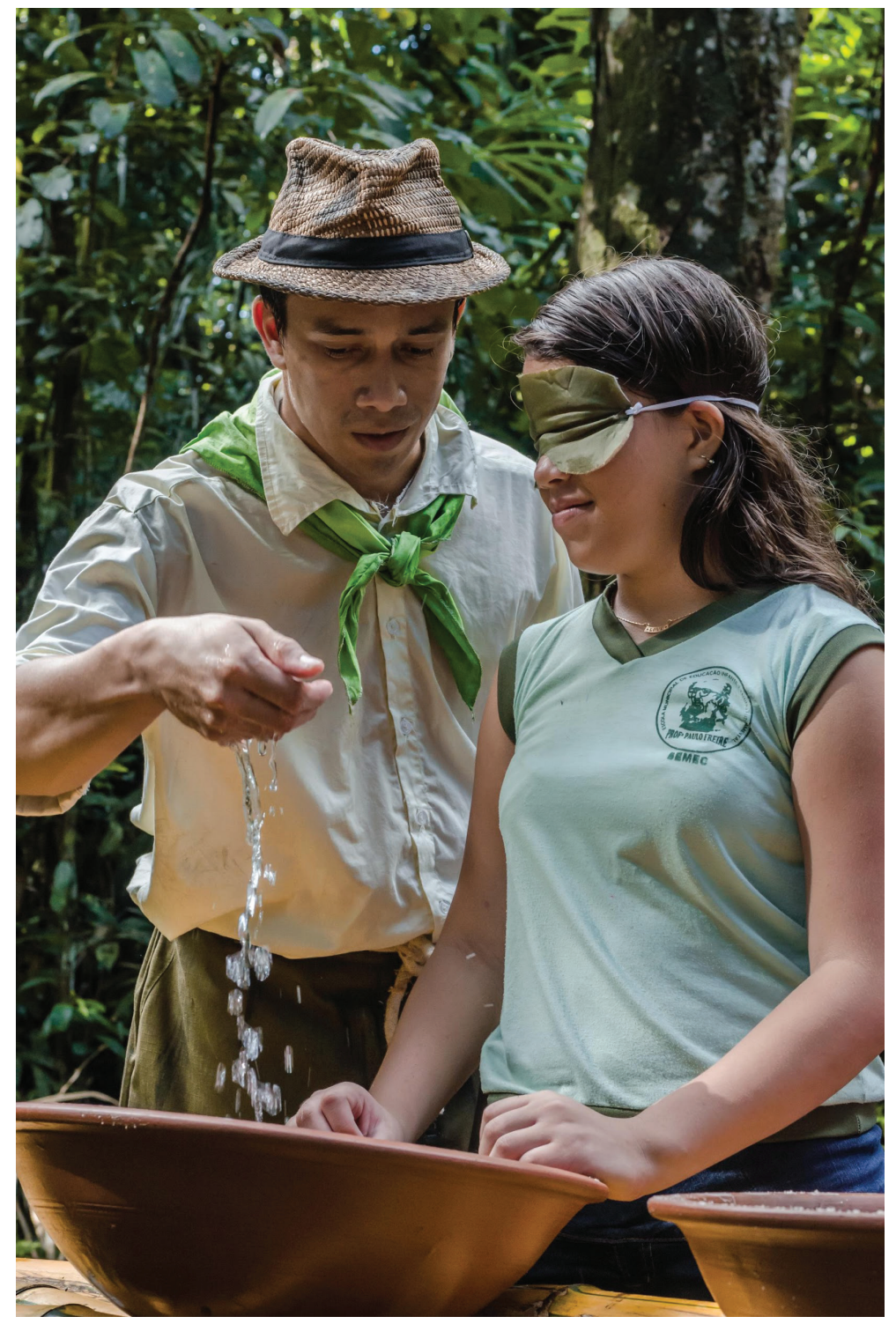


60 EXPERIM E N T $\bigwedge$ R T Ano 2 -n. 3-jul./dez. 2016 - ISSN 2526-7736
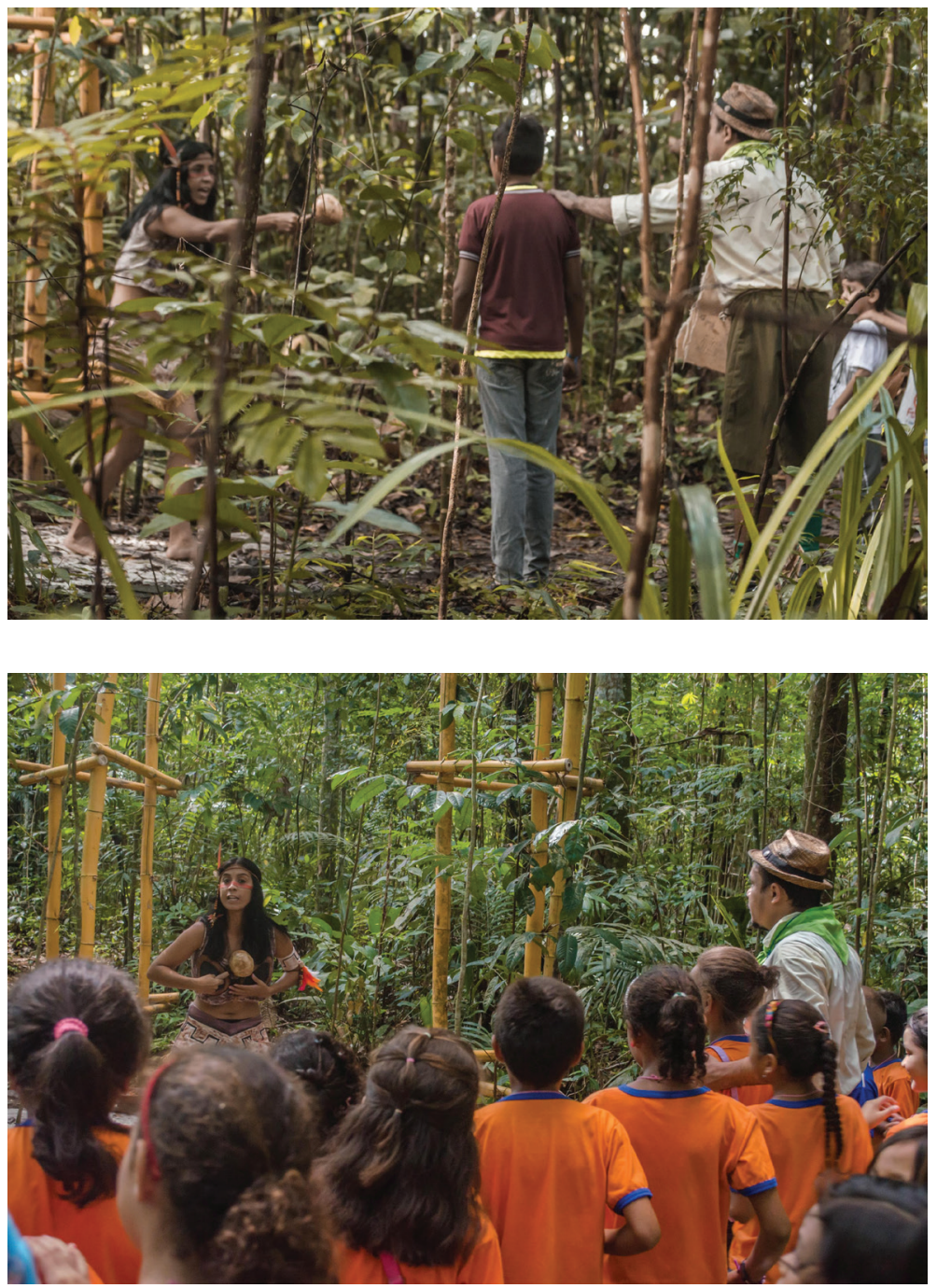

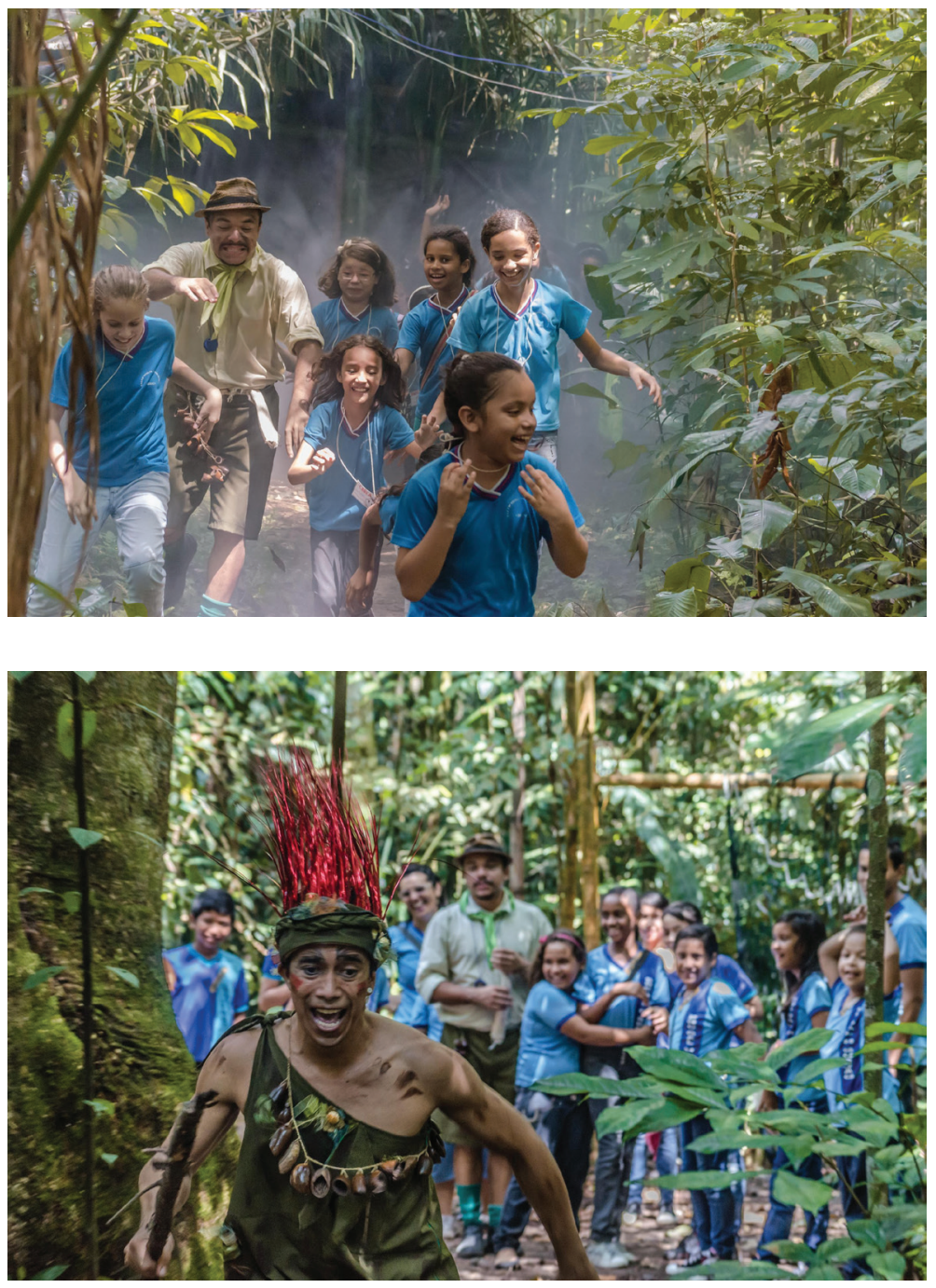

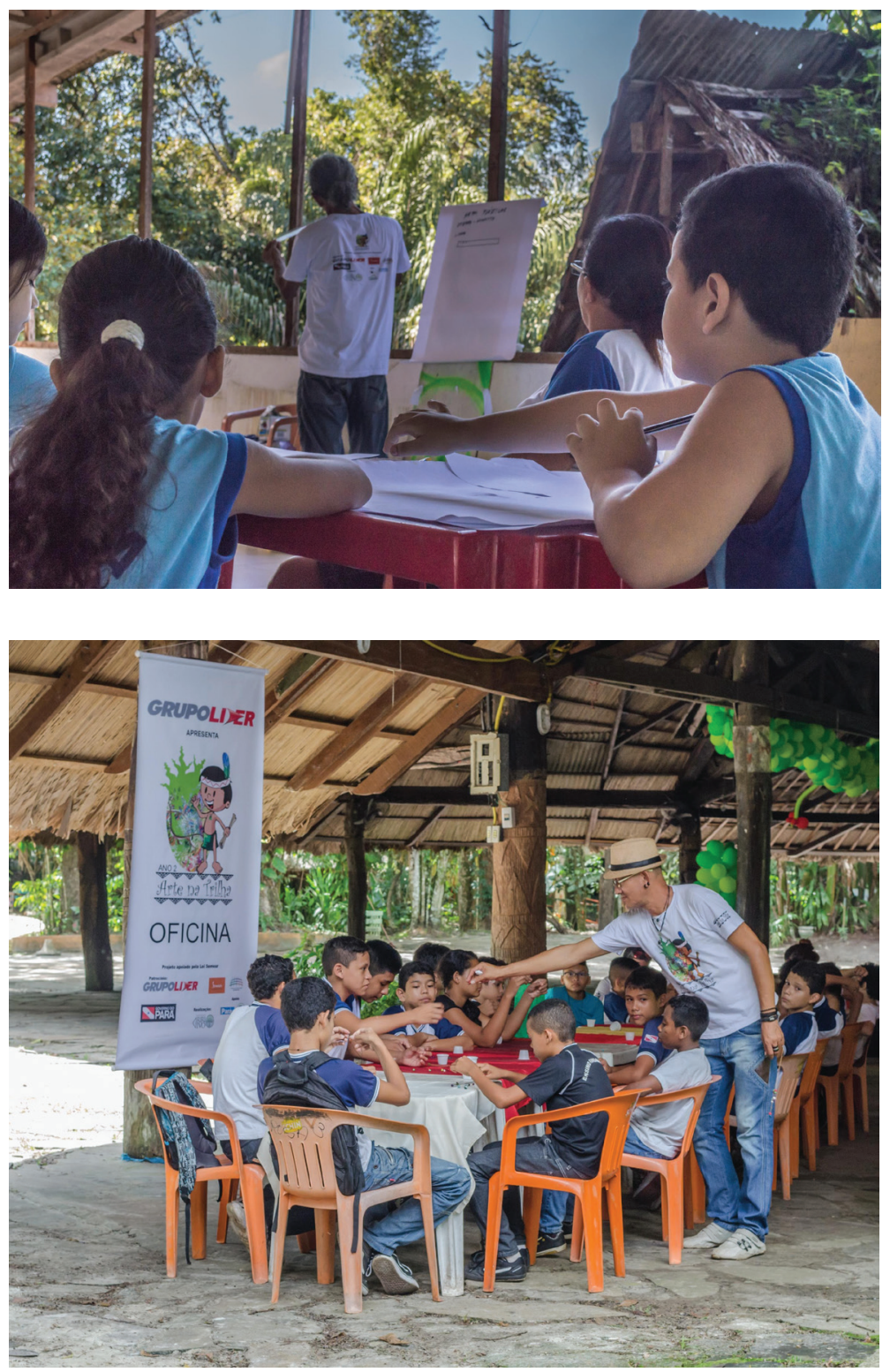

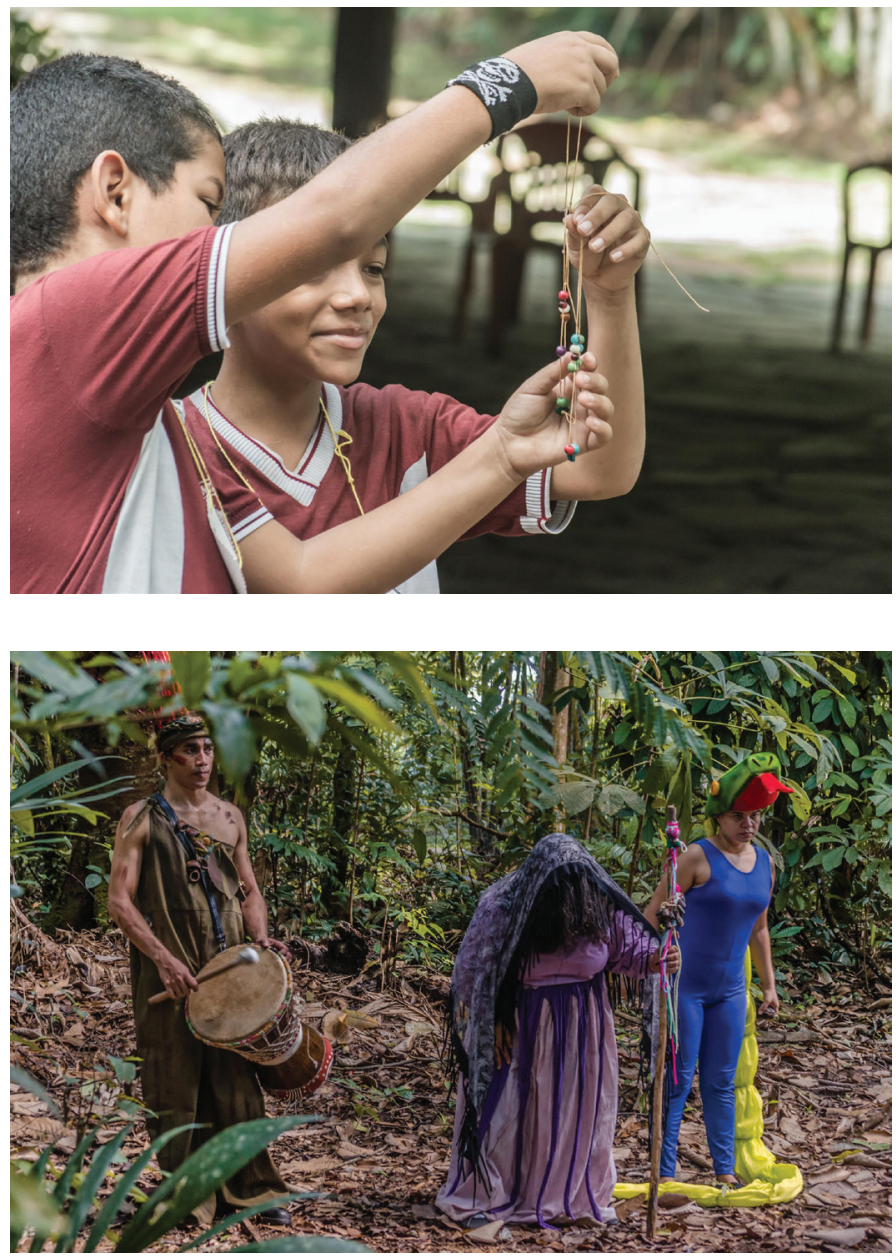

Flavio Augusto da Silva Contente é fotógrafo de Sociobiodiversidade, Diretor de Relações Institucionais Instituto Ariri Vivo.

Uirá Seidl Pinheiro é Diretor Geral do Instituto Ariri Vivo.

Ariadne da Costa Peres Contente é professora do Instituto de Educação Matemática e Científica (IEMCI) da Universidade Federal do Pará. 